\title{
Study on the Reserve Distribution Model of Light Weapons
}

\author{
Zhen Li and Jian Gao \\ Department of Equipment Command and Administration Army Engineering University, Shijiazhuang, China
}

\begin{abstract}
In view of the lack of pertinence in the weapon equipment maintenance capability evaluation, combining the characteristics of light weapon equipment, the index model of light weapon support capability is established. A variety of mathematical models and methods have been applied to the study of the construction of light weapon reserves. Through comprehensive analysis, the simulation results show that the model has achieved remarkable results.
\end{abstract}

\section{Keywords—light weapon; reserve constuctiont; model}

Equipment management is the important foundation for combat effectiveness generation, and is also important for the army's equipment construction in a global, basic and regular way. Under the new historical conditions, the management of grass-roots weaponry and equipment should be guided by the thought of chairman Hu's military construction, based on existing equipment, existing conditions and own strength, focusing on the needs of the future high-tech war and the development of weapons and equipment, adhering to the implementation of the regulations and regulations of the management of weapons and equipment, and effectively solving the constant protection of weapons and equipment, Mastering weapons and equipment, strict management of weapons and equipment, meticulous maintenance of weapons and equipment, efforts to improve the scientific, institutionalized and regular management of weapons and equipment, to promote the best combination of weapons and equipment, and improve the combat effectiveness of the army ${ }^{[1-2]}$.

\section{NeW Thought OF EQUiPMENT MANAGEMENT}

With the improvement of the modernization level of weapons and equipment, in the face of increasing maintenance costs, we should attach importance to the development of new concept of weapon equipment management and find solutions from the concept of renewal management.

\section{A. Pay Attention to the System Management of Weapons and Equipment}

The system management of the so-called weapon equipment is to treat the weapon and equipment as a whole from ensuring the overall operational capability of the troops, and carry out comprehensive and systematic management. To carry out this idea, we should start with two aspects. On the one hand, we should consider all the weapons and equipment allocated by each unit as a system, and focus on the effective management of the system. Because the basic unit's weaponry is not isolated and single, but a subsystem of the whole army's weapon system. In modern warfare, only the technical performance of each single piece of equipment can be fully developed, and the overall combat power can be formed to ensure that the grass-roots units accomplish the tasks of wartime or peacetime. On the other hand, it is necessary to put every equipment and equipment unit as a system to implement better management. Because any modern equipment and any equipment unit of the grass-roots unit is made up of several parts and components, and any part of the equipment failure will affect the function of the whole equipment system. Therefore, grass-roots units should establish a system concept for each equipment and each equipment unit, and pay attention to various specific management problems according to the performance of each part of the equipment, the requirements of use, the degree of vulnerability and so on.

\section{B. Pay Attention to the Whole Process Management of Weapons and Equipment}

The whole process management of weaponry means that from the beginning of the equipment and distribution to the grass-roots unit, to the whole period of retirement or discarding, the grass-roots units must master the regularity of the whole process management of the acceptance, transfer, storage, maintenance, repair and repair of the weapons and equipment, and carry out effective management. Because in this whole process, any stage of bad management will seriously affect the effectiveness of the entire equipment management.

\section{Pay Attention to the Implementation of Whole Staff Management}

With the continuous improvement of the modernization of weapons and equipment, weapons and equipment become increasingly complex, the officers and soldiers on different posts have certain professional scope, bear the responsibility of the management of weapons and equipment, and are difficult to replace each other. Only by implementing full management can the specialization level of arms management be improved, and then the integrity of the weapons and equipment at the grass-roots units can be improved, and the full play of the grass-roots combat effectiveness can be ensured.

\section{II.THE SENSE OF RESPONSIBILITY IN MANAGING ARMS AND EQUIPMENT}

A strong sense of professionalism and sense of responsibility is the first condition for doing everything well, and is also the ideological basis for managing well used weapons and equipment. Leaders at the grass-roots level and all officers and men should start with improving their 
ideological understanding and constantly enhance their sense of responsibility and self-consciousness in doing well the management of weaponry and equipment.

\section{A. Strengthen Education and Raise Awareness}

Some units of weapons and equipment management work do not go up, in the low level of hovering, the first reason is that some officers and soldiers on the status and role of weapons and equipment management of vague understanding, ideological and attitude and work guidance is not correct. There are some paralyzed thoughts that have been forgotten, and the relatively peaceful environment is regarded as absolute and permanent; the judgement that the strategic war can not get up at a sudden is regarded as the possibility that some of the troops in some parts of the region are not involved in the war; some have the extreme "left" thought of the spiritual omnipotence, and the basis for neglecting the basis of the material factors in the war. We can not see that the wave of technological revolution has brought out a new era of the development of weaponry and equipment; some are pessimistic and pessimistic, that the development level of our armaments is not high, far from the developed countries, and the lack of confidence in the existing weapons and equipment to defeat the enemy. In this regard, we must set up the idea of teaching first, guide the officers and soldiers to fully understand the dialectical relationship between men and weapons from the aspects of meaning, responsibility, common sense, tradition, lesson, situation and national conditions, fully understand the relationship between strengthening the management of weapons and equipment and improving the combat effectiveness of the troops, and fully recognize the good use of good weapons and equipment for every serviceman. It is incumbent on the responsibility to firmly establish the confidence in winning the battle based on the existing equipment, and to conscientiously do a good job in the management of weapons and equipment with a high level of responsibility for the security of the country and the construction of the army. We should pay attention to the effect of the management of clothing and clothing education. We should organize people to manage the content, have teaching materials on content, guarantee time, and check after education.

\section{B. Clear Responsibilities and Participate in Management}

Some of the units are not enough to carry out the activities of erotic loading and unloading. An important reason is that the responsibilities of a considerable part of the officers and men in equipment management are not clear. The regulations on the management of the PLA's weapons and equipment has made clear, specific and detailed provisions on the responsibilities of the heads of all levels, organs and all military personnel in the management of weapons and equipment. All soldiers must be familiar with their duties, perform their duties, and translate the terms of their duties into conscious action. Strengthening weaponry management is not only a matter of leading bodies, but also a matter of grassroots cadres. Whether it is an administrative cadre or a technical cadre, whether it is an ordinary soldier or a technical soldier, whether it is a combatant or a service guarantee personnel, they should manage their arms and equipment well in their respective positions to ensure that the weapons and equipment are often in a good state of technology. As a whole, it is not only for the grass-roots officers and men to save their weapons and equipment, but everyone should learn the common sense of weaponry and equipment. Everyone must master their arms and equipment. Everyone should carefully maintain their weapons and equipment. Everyone wants to manage their weapons well and realize human loading. The best combination is to enhance the combat effectiveness of the army and make contributions and contribute.

\section{Leading Cadres are the first to be Exemplar}

The grass-roots cadres are in the leading position in all kinds of work, and they have the double responsibility of organizing leadership and taking the lead. In the management of weapons and equipment, grass-roots cadres should not only carefully plan, organize and implement, but also take the lead in the love of weapons and equipment, take the lead in carrying out "three familiar", "four meetings" training, take the lead in wiping and maintenance and maintenance of weapons and equipment, leading the development of weapons and equipment technology innovation and so on. If the cadres are not familiar with the weapons and equipment, especially the technical performance of the new weapons and equipment, it will become an outsider. The "blind" command often occurs in the management, and the phenomenon of "disorderly" command is not on the point of mind. If we are not familiar with the regulations and requirements of the daily management of weaponry and equipment, the management work will be organized and the phenomenon of "the Dongyi hammer in the west" appears to affect the overall effect and quality of the management of weapons and equipment. If the number of weapons and equipment is not familiar with the number of quality, work will not be targeted, not only to affect the completion of operations, training and other tasks, but also to the damage, loss, theft and other weapons and equipment to cause a chance. Therefore, in the management of weapons and equipment, cadres at the grass-roots level must play a good role in organizing leadership and exemplary leading, leading the soldiers to manage their equipment, use well and repair equipment with their own practical actions. As long as the leaders attach importance to them and cadres take the lead, they can fully mobilize the enthusiasm of the fighters, and the management of weaponry and equipment will also be able to achieve efficiency and level.

\section{LAWS AND REGULATIONS GOVERNING WEAPONS AND EQUIPMENT MANAGEMENT}

Laws and regulations are the basic basis for the implementation of weapons and equipment management at the grass-roots level. Strictly implementing the regulations and regulations is an important guarantee for doing well in the management of weaponry and equipment. As the saying goes, "no rules, no Cheng Fangyuan." No matter what we do, we must have corresponding regulations, requirements and yardstick, otherwise we can not get a happy ending. The regulations and relevant provisions of weapon and equipment management are the "rules" and "moments" for the implementation of weapons and equipment management, which must be observed and implemented strictly. 


\section{A. Strengthening the Consciousness of Legal Installation}

In the past, some units had problems in the management of weaponry and equipment, such as flexibility, reduction of standards, punishment by escrow, and tight time. The main reason is that some officers and men have weak sense of regulations and poor sense of law enforcement. Strengthening the consciousness of legal installation is to make the majority of the officers and soldiers fully aware of the important role of the laws and regulations in the management of weapons and equipment through education and guidance. In accordance with the law, it is the objective requirement of the scientific, institutionalized and regular management of weapons and equipment. No matter the cadres or the soldiers, it is necessary to use the rules and regulations to regulate and conduct, no one should have an "exception", the troops are all walks of life and carry out various tasks. The Department must be installed in accordance with the law, scientific installation, and no "special" in any aspect, and the strict implementation of the rules and regulations should be carried out throughout the installation and installation work. There must be no "intermittent". At the same time, it should be seen that with the wide use of high and new technology in the military field, the rapid development of weapons and equipment, its system more complex, more precise structure, more difficult management, and the urgent need to use laws and regulations to maintain the strict, normative, and accurate of weapons and equipment management. Careful and scientific and efficient operation of weapons and equipment management mechanism $^{[3]}$.

\section{B. Familiarity with the Content of the Rules and Regulations}

Familiarity with laws and regulations and mastery of standard requirements are prerequisites for managing according to law. One of the most important reasons is that laws and regulations are not implemented and management is not regular. In the decades of war and construction practice, our army has constantly summed up a series of management systems of weaponry and equipment with our military characteristics. To sum up, it mainly includes ten aspects, such as post responsibility system, transfer system, safekeeping system, inspection and inspection system, registration of statistical air, use and storage system, maintenance system, retirement system, security and confidentiality system, evaluation and punishment system and so on. These systems involve all aspects of weaponry management and fully reflect the whole process of weaponry management. Every grass-roots unit should take the learning and training of the ten systems of regulations and equipment management as the required courses for the cadres and soldiers, and take the methods of general reading, knowledge competition, and examination questions, so that every officer and soldier will become a "rule" and a "system".

\section{Strict Administration According to Laws and Regulations}

According to the strict regulation of regulations, it is in the process of weapon and equipment management that we should act according to the regulations and regulations, so that we must obey the law and punish the law. Only when law enforcement is strict and rewards and punishments are fair, can the seriousness and authority of laws and regulations be maintained, and the effective implementation of laws and regulations can be ensured. The implementation of laws and regulations governing weaponry must be strict, fair and accurate. For all personnel, including officers at all levels, they must be strict in terms of usage and regulations. They must not be strict. In order to carry out the rules and regulations in all aspects and the whole process of military equipment management, we should adhere to regular, pay attention to nurturance, not sometimes strict, sometimes loosely, and carry out rewards and punishments strictly according to the prescribed standards and procedures. . We must resolutely abolish the "local policies" which are contrary to the regulations and relevant provisions, and safeguard the seriousness of the laws and regulations on weaponry and equipment. In order to replace the law by the right of power, the will of the governor, the will of the chief, the individual, or the other set up in violation of the laws and regulations can not only promote the effective implementation of the legal system, but sometimes even weaken the negative effect of the management and disturbance of the order ${ }^{[4]}$.

\section{REFERENCES}

[1] Yao Kay, Guo Shizhen, Fu Xiaozhong, and so on. The scale control model of ammunition physical reserve construction [J]. equipment college journal, 2016, 27 (1): 52-56.

[2] Summer Changchun. Elementary introduction to the direction of the development of light weapons technology [J]. scientists, 2017 (3): 18-19.

[3] Jiang Da. Military logistics system model and application of [M]. Chinese material press, 2006.

[4] He Jianfeng, Li Cui. New high, future war weapons and equipment production capacity on the construction of [J]. automation, 2014 (10): 4-6. 